\title{
ESTIMATION OF STRONG GROUND MOTIONS IN MEXICO CITY EXPECTED FOR LARGE EARTHQUAKES IN THE GUERRERO SEISMIC GAP
}

\author{
By Hiroo Kanamori, Paul C. Jennings, Shri Krishna Singh, \\ AND LUCIANA Astiz
}

\begin{abstract}
We performed simulations of ground motions in Mexico City expected for large earthquakes in the Guerrero seismic gap in Mexico. The simulation method uses as empirical Green's functions the accelerograms recorded in Mexico City during four small to moderate earthquakes (8 Feb. 1988, $M_{s}=5.8$; 25 April 1989, $M_{w}=6.9 ; 11$ May 1990, $M_{w}=5.5$; and 31 May 1990, $M_{w}=6.0$ ) in the Guerrero gap. Because these events occurred in the Guerrero gap, and have typical thrust mechanisms, the propagation path and site effects can be accurately included in our simulation. Fault rupture patterns derived from the 1985 Michoacan earthquake and source scaling relations appropriate for Mexican subduction zone earthquakes are used. If the Guerrero event is similar to the 1985 Michoacan event, the resulting response spectrum in Mexico City will be approximately twice as large as that of the 1985 Michoacan earthquake at periods longer than 2 sec. At periods shorter than $2 \mathrm{sec}$, the amplitude will be 2 to 3 times larger than that for the Michoacan earthquake. If the events in the Guerrero seismic gap occur as a sequence of magnitude 7.5 to 7.8 events, as they did in the previous sequence around the turn of the century, the strong motion in Mexico City is estimated to be about half that experienced during the $\mathbf{1 9 8 5}$ Michoacan earthquake at periods longer than 2 sec. However, several factors affect this estimate. The magnitude of the possible events has a significant range and, if a rupture sequence is such that it enhances ground-motion amplitude with constructive interference, as occurred during the second half of the Michoacan sequence, some components of the ground motion could be amplified by a factor of 2 to 3 . To aid in the interpretation of the simulated motion for purposes of design or hazard assessment, design spectra for the CDAO site in Mexico City are derived from the response spectra of the simulated ground motions.
\end{abstract}

\section{INTRODUCTION}

The Michoacan, Mexico, earthquake of 19 September 1985, $\left(M_{w}=8.1\right)$ is the most damaging event to date in that country. Along the Mexican subduction zone, about 10 earthquakes with $M_{s}>7.5$ have occurred during the past $60 \mathrm{yr}$ (Singh et al., 1981) (Fig. 1). Although the magnitudes of these events are almost comparable to the 1985 Michoacan earthquake, none of them caused as much damage in Mexico City as the 1985 Michoacan earthquake.

Although many of the seismic gaps along the Mexican coast have been filled by large earthquakes during the last two decades (Singh et al., 1981; Astiz and Kanamori, 1984), a prominent gap in Guerrero, which begins roughly about 100 $\mathrm{km}$ from the SE end of the Michoacan rupture zone, has not broken since 1911 (Fig. 1). The size of this gap is comparable to that of the Michoacan gap. Many seismologists suggest (Anderson et al., 1989) that the Guerrero gap is likely to break in the next decade or so. 


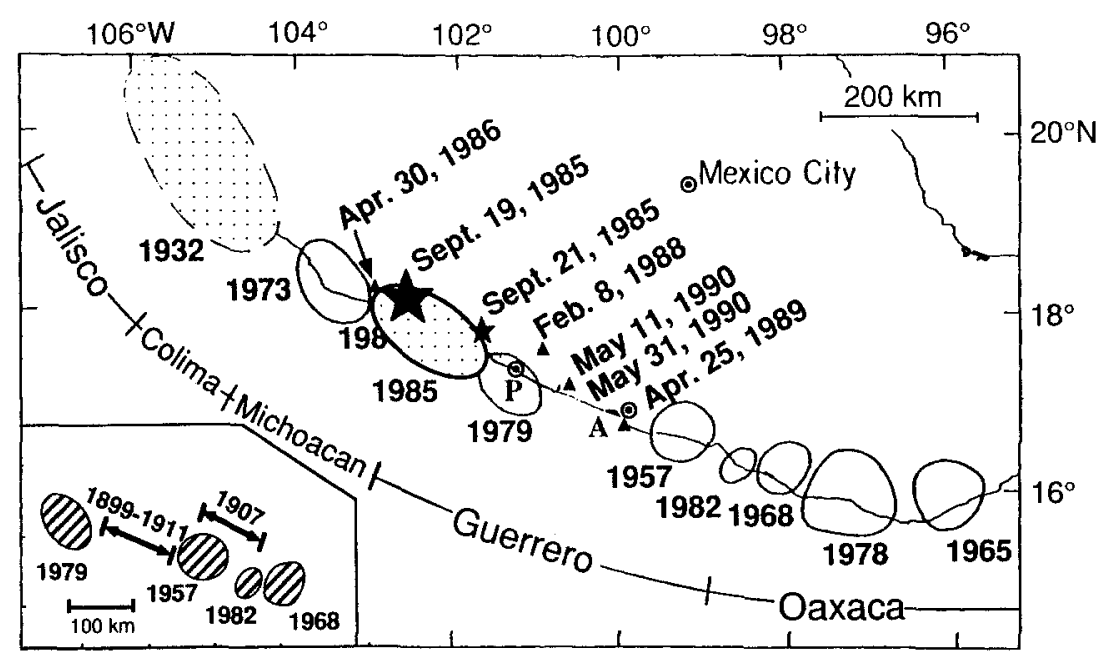

Fig. 1. Rupture zones of major earthquakes along the southwest coast of Mexico. The inset shows the Guerrero seismic gap.

In view of this unique situation, we performed simulations of ground motions expected in Mexico City from hypothetical earthquakes in the Guerrero gap. This simulation is based on the results of detailed studies on the mechanism, rupture pattern, and source spectra of the Michoacan earthquake and other major events in Mexico (Houston and Kanamori, 1986a; Astiz et al., 1987; Houston, 1987). Because the results obtained for the Michoacan earthquake are the basis of this simulation, we first summarize them in the following section.

\section{MICHOACAN EARTHQUAKE}

Extensive studies on the 1985 Michoacan earthquake have been made by various investigators' (UNAM Seismology Group, 1986; Eissler et al., 1986; Anderson et al., 1986; Ekström and Dziewonski, 1986; Astiz et al., 1987). The earthquake has a low-angle thrust mechanism typical of Mexican subductionzone earthquakes. The source consists of two major events about $90 \mathrm{~km}$ and 25 sec apart. Houston (1987) deconvolved body waves observed at many stations worldwide and obtained the fault rupture pattern shown in Figure 2 and Table 1 . In this particular solution, the source consists of approximately 50 subevents with seismic moments ranging from $3 \times 10^{25}$ to $2 \times 10^{26}$ dyne-cm. Each subevent is characterized by the seismic moment $m_{i}$ and the onset time $\tau_{i}$. Although the solution is not unique, it is similar to the results obtained by other investigators (e.g., Mendoza and Hartzell, 1989; Mendez and Anderson, 1991) and can be considered a good approximation of the actual fault rupture pattern. Although the seismic moment estimated from long-period surface waves is about $1.1 \times 10^{28}$ dyne-cm, the total seismic moment obtained from body waves is $0.445 \times 10^{28}$ dyne-cm, as shown in Table 1 . Because we are primarily concerned with the period range of body waves in our simulation, we will use the seismic moment determined from the body-wave analysis.

\section{Simulation METHOD}

The simulation method is similar to the one used in Kanamori (1979), and uses observed accelerograms as an empirical Green's function (Hartzell, 1978). 

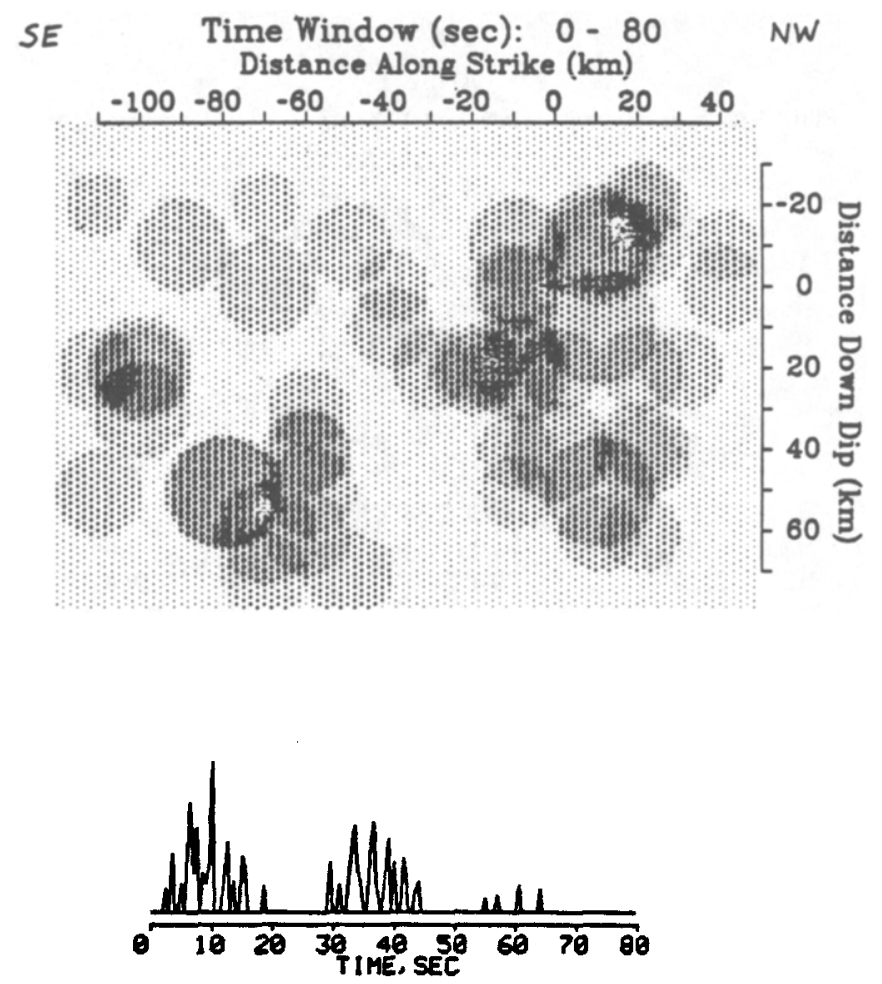

FIG. 2. (a) Spatial distribution of subevents for the 1985 Michoacan earthquake. The circles indicate the approximate rupture area of the subevents. (b) Temporal variation of seismic moment of the rupture sequence shown in (a). The details are given in Table 1.

The empirical Green's function method has been used successfully to explain waveforms of large earthquakes. In this study, we used recorded accelerograms from small events in the Mexican coastal areas recorded in Mexico City as the empirical Green's functions (Table 2). In addition, we employed source scaling relations determined for large subduction zone earthquakes (Hartzell and Heaton, 1985; Houston and Kanamori, 1986b; Zhuo and Kanamori, 1987) to approximate the ground motions from each subevent shown in Figure 2.

Let $f_{i}\left(t-\tau_{i} ; m_{i}\right)$ be the ground motion observed at a site from the $i$-th subevent with the seismic moment $m_{i}$ and the onset time $\tau_{i}$. Then the ground motion from the total event is

$$
s(t)=\sum_{i=1}^{N} f_{i}\left(t-\tau_{i} ; m_{i}\right)
$$

where $N$ is the total number of subevents.

We use the ground motion from a reference event $f_{r}\left(t ; m_{r}\right)$ as the empirical Green's function. We use as reference events small to moderate earthquakes in the same epicentral region as the main shock to be modelled. Then using a seismic scaling relation, we write

$$
\left|\hat{f}_{i}\left(\omega ; m_{i}\right)\right|=\hat{T}\left(\omega ; m_{i}, m_{r}\right) \cdot\left|\hat{f}_{r}\left(\omega ; m_{r}\right)\right|
$$


TABLE 1

The Rupture Pattern of the 1985 Michoacan Earthquake

\begin{tabular}{|c|c|c|c|c|}
\hline Event & $t(\mathrm{sec})$ & $x(\mathrm{~km})$ & $y(\mathrm{~km})$ & $\begin{array}{c}m \\
\left(10^{25} d y n e-c m\right)\end{array}$ \\
\hline 1 & 2.5 & 10 & 0 & 5.7 \\
\hline 2 & 3.5 & 10 & 10 & 4.9 \\
\hline 3 & 3.5 & 10 & 0 & 9.2 \\
\hline 4 & 5.0 & 0 & 20 & 6.9 \\
\hline 5 & 6.0 & 10 & 20 & 14.5 \\
\hline 6 & 6.5 & 10 & 20 & 7.6 \\
\hline 7 & 6.5 & -10 & 10 & 18.6 \\
\hline 8 & 7.0 & -20 & -20 & 4.1 \\
\hline 9 & 7.0 & 20 & 20 & 5.3 \\
\hline 10 & 7.5 & -10 & -10 & 20.4 \\
\hline 11 & 8.5 & 20 & 20 & 9.4 \\
\hline 12 & 9.0 & 30 & 20 & 6.8 \\
\hline 13 & 9.5 & -10 & -10 & 12.2 \\
\hline 14. & 10.0 & -20 & -10 & 8.0 \\
\hline 15 & 10.0 & 10 & -10 & 10.3 \\
\hline 16 & 10.0 & 0 & 40 & 12.8 \\
\hline 17 & 10.0 & 40 & 0 & 5.1 \\
\hline 18 & 12.0 & -20 & -20 & 8.2 \\
\hline 19 & 12.5 & -10 & 50 & 16.8 \\
\hline 20 & 13.5 & -20 & 20 & 7.5 \\
\hline 21 & 15.0 & -40 & 0 & 7.1 \\
\hline 22 & 15.0 & -10 & 60 & 6.4 \\
\hline 23 & 15.5 & -20 & 40 & 11.0 \\
\hline 24 & 18.5 & -20 & 60 & 6.2 \\
\hline 25 & 29.5 & 70 & 0 & 11.9 \\
\hline 26 & 31.0 & 60 & 40 & 6.7 \\
\hline 27 & 32.5 & 60 & 40 & 8.1 \\
\hline 28 & 33.0 & 110 & 50 & 7.7 \\
\hline 29 & 33.0 & 40 & 10 & 7.1 \\
\hline 30 & 33.5 & 60 & 30 & 6.7 \\
\hline 31 & 33.5 & 100 & 20 & 14.0 \\
\hline 32 & 34.0 & 60 & 50 & 10.1 \\
\hline 33 & 34.5 & 50 & -10 & 7.4 \\
\hline 34 & 36.0 & 80 & 50 & 17.1 \\
\hline 35 & 36.5 & 90 & -10 & 9.9 \\
\hline 36 & 36.5 & 100 & 30 & 11.6 \\
\hline 37 & 37.0 & 60 & 60 & 7.6 \\
\hline 38 & 37.5 & 70 & -20 & 3.6 \\
\hline 39 & 38.5 & 50 & 70 & 8.4 \\
\hline 40 & 39.0 & 80 & 50 & 17.4 \\
\hline 41 & 40.0 & 110 & 20 & 6.8 \\
\hline 42 & 40.0 & -20 & 40 & 5.1 \\
\hline 43 & 41.5 & 70 & 60 & 12.8 \\
\hline 44 & 42.0 & 100 & 20 & 8.7 \\
\hline 45 & 43.5 & 10 & 50 & 5.0 \\
\hline 46 & 44.0 & 70 & 70 & 7.3 \\
\hline 47 & 55.0 & 110 & -20 & 3.3 \\
\hline 48 & 57.0 & -40 & -10 & 4.2 \\
\hline 49 & 60.5 & -30 & 20 & 6.3 \\
\hline \multirow[t]{2}{*}{50} & 64.0 & 10 & 40 & 5.5 \\
\hline & & & Total & 445.3 \\
\hline
\end{tabular}


TABLE 2

EARTHQUAKES USED AS REFERENCE EVENTS

\begin{tabular}{ccccc}
\hline No. & \multicolumn{1}{c}{ Date } & $M_{s}$ or $M_{w}$ & Latitude & Longitude \\
\hline 1 & $9 / 21 / 1985$ & 7.6 & 17.6 & 101.8 \\
2 & $4 / 30 / 1986$ & 6.9 & 18.3 & 102.9 \\
3 & $2 / 8 / 1988$ & 5.8 & 17.0 & 100.4 \\
4 & $4 / 25 / 1989$ & 6.9 & 16.8 & 99.4 \\
5 & $5 / 11 / 1990$ & 5.5 & 17.3 & 100.7 \\
6 & $5 / 31 / 1990$ & 6.0 & 17.3 & 100.8 \\
\hline
\end{tabular}

where $\hat{f}_{r}\left(\omega ; m_{i}\right)$ and $\hat{f}_{r}\left(\omega ; m_{r}\right)$ are the Fourier transforms of,$\left(t ; m_{i}\right)$ and $f_{r}\left(t ; m_{r}\right)$ respectively, and $\omega$ is the angular frequency. Here $\hat{T}\left(\omega ; m_{i}, m_{r}\right)$ is the ratio of the source amplitude spectrum of the $i$-th event to that of the reference event. We can use either an empirical or theoretical scaling relation appropriate to the Mexican subduction-zone events. Houston and Kanamori (1986b) showed that the following $\omega^{2}$ source model is a good approximation for five Mexican subduction-zone events:

$$
\hat{\dot{M}}(\omega)=M_{0} \frac{\omega_{c}^{2}}{\omega^{2}+\omega_{c}^{2}}
$$

where $\hat{\dot{M}}(\omega)$ is the seismic moment rate spectrum, $M_{0}$ is the seismic moment, and $\omega_{c}$ is the corner angular frequency which is given by

$$
\omega_{c}=3.08 \beta\left(\Delta \sigma / M_{0}\right)^{1 / 3} .
$$

Here $\Delta \sigma$ is the stress parameter and $\beta$ is the shear velocity (Brune, 1970, 1971; Boore, 1983). Using (2), we obtain

$$
\hat{T}\left(\omega ; m_{i}, m_{r}\right)=\left(\frac{m_{i}}{m_{r}}\right)^{1 / 3} \cdot \frac{\omega^{2}+\omega_{r}^{2}}{\omega^{2}+\omega_{i}^{2}}
$$

where $\omega_{i}$ and $\omega_{r}$ are the corner angular frequencies of the $i$-th event and the reference event, respectively.

Assuming that the phase spectrum does not change with the event size, we can write the ground motion for the $i$-th event as

$$
f_{i}\left(t-\tau_{i} ; m_{i}\right)=\frac{1}{2 \pi} \int_{-\infty}^{+\infty} e^{-i \omega \tau_{i}} \hat{T}\left(\omega ; m_{i}, m_{r}\right) \hat{f}_{r}\left(\omega ; m_{r}\right) e^{i \omega t} d \omega ;
$$

then the total ground motion is given by (1).

Since performing the transform (5) for all the subevents is time consuming, we perform the above computation in the frequency domain. Taking the transform of (1), and using the above relations, we obtain

$$
\hat{s}(\omega)=\hat{f}_{r}\left(\omega ; m_{r}\right) \sum_{i=1}^{N}\left(\frac{m_{i}}{m_{r}}\right)^{1 / 3} \frac{\omega^{2}+\omega_{r}^{2}}{\omega^{2}+\omega_{i}^{2}} e^{-i \omega \tau_{i}} .
$$


We first compute $\hat{s}(\omega)$ using $m_{i}, m_{r}$, and $\tau_{i}\left(\omega_{i}\right.$ and $\omega_{r}$ are obtained from $m_{i}$ and $m_{r}$ using (3)), and then inverse transform it to obtain $s(t)$.

In our simulation we assumed that $\Delta \sigma$ is $30 \mathrm{bars}, \beta$ is $3.5 \mathrm{~km} / \mathrm{sec}$, and the phase of subevents does not depend on the event size. We will later discuss the effect of these assumptions.

\section{Test OF THE METHOD}

First we tested our method for the Michoacan earthquake. We used strong ground motions from two aftershocks of the 1985 Michoacan earthquake recorded in Mexico City as the empirical Green's functions. We used the subevent sequence shown in Table 1 for this simulation. Although we did not test other rupture models presented by other investigators, a direct comparison of our results with the observed data indicates that our simulation is reasonable on an empirical basis too, as we will show later.

Figures $3 \mathrm{a}$ and $3 \mathrm{~b}$ show the strong-motion record of the 21 September 1985 aftershock (used as the empirical Green's function), simulated ground motion, and the observed ground motion for the main shock. For the 21 September 1985 event we used the seismic moment $1.2 \times 10^{27}$ dyne-cm determined from body waves (Astiz et al., 1987). The accelerograms were recorded digitally with a
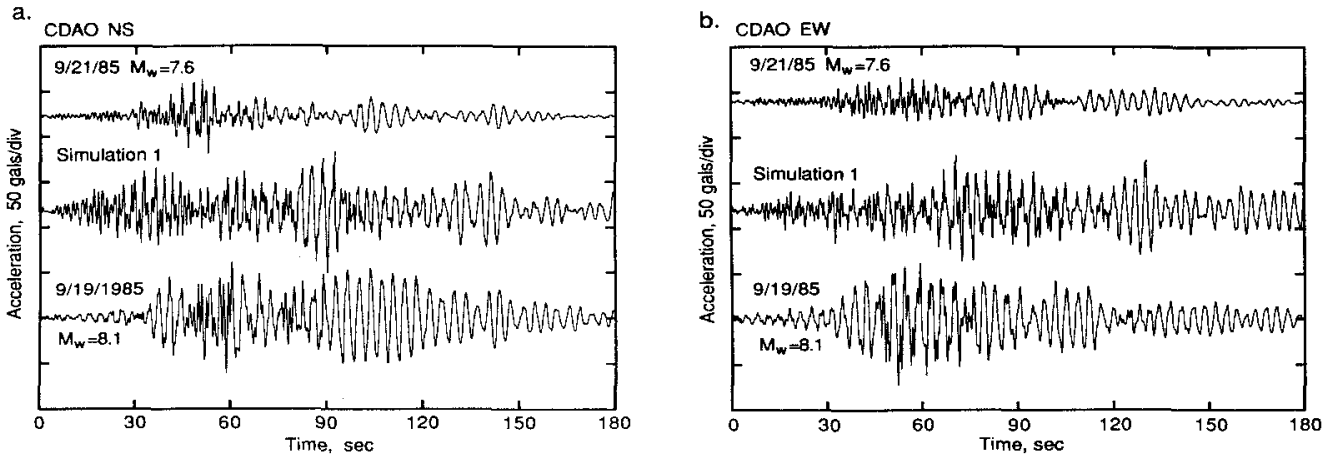

c.
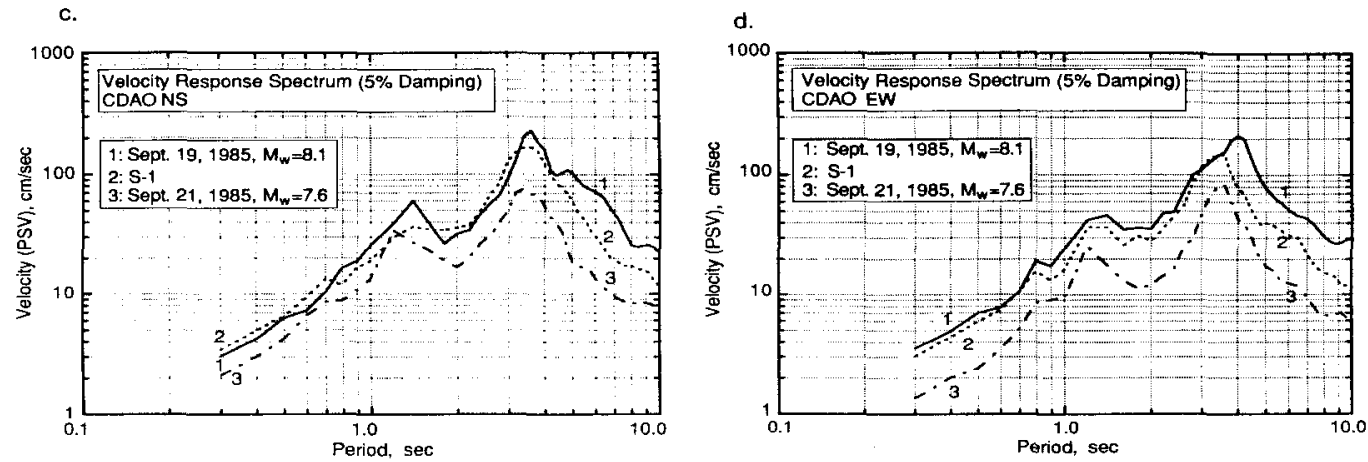

FIG. 3. (a) Time histories of N-S ground-motion acceleration at the site in Mexico City. The top trace is the acceleration record of the 21 September 1985 earthquake, which is used for the empirical Green's function. The bottom trace is the acceleration record of the 19 September 1985 Michoacan earthquake, shown as reference. The middle traces are the simulated ground motion using the Michoacan rupture sequence shown in Figure 2. (b) Time histories of $E-W$ ground-motion acceleration at the CDAO site in Mexico City. (c) The velocity response spectra (5\% damping) computed for the time histories shown in Figure 3a. (d) The velocity response spectra (5\% damping) computed for the time histories shown in Figure $3 \mathrm{~b}$. 
force-balance accelerograph at a lake-bed site (CDAO) in Mexico City. The CDAO site has an approximately $30-\mathrm{m}$ thick clay layer with a shear velocity of about $70 \mathrm{~m} / \mathrm{sec}$. More details are given in table 1 of Sanches et al. (1988). The corresponding velocity response spectra (PSV, 5\% damping) are shown in Figures 3c and 3d. Although the waveform of the simulation differs in detail from the observed ground motion, the overall shape of the waveform and the response spectrum of the simulated motion is very similar to the observed, indicating that our simulation method works well. The spectra of the simulations are lower than the observed spectra at long periods, however.

We note that, for the $\mathrm{E}-\mathrm{W}$ component, the peak of the response spectrum of the main shock occurs at $4 \mathrm{sec}$ whereas that of the simulated motions occurs at 3.4 sec. Inspection of the Fourier spectra of these records indicates that this difference is not an artifact of sampling of the spectrum, but is real. First, this difference was thought to be a manifestation of nonlinearity of the lake-bed material, but Singh et al. (1988b, 1990) show that this shift is probably caused by an enhanced source spectrum of the main shock at periods longer than $3.5 \mathrm{sec}$.

Figures $4 \mathrm{a}, 4 \mathrm{~b}, 4 \mathrm{c}$, and $4 \mathrm{~d}$ show the results of simulation in which the records from a smaller aftershock $\left(M_{w}=6.9,30\right.$ April 1986) are used as the Green's

a.

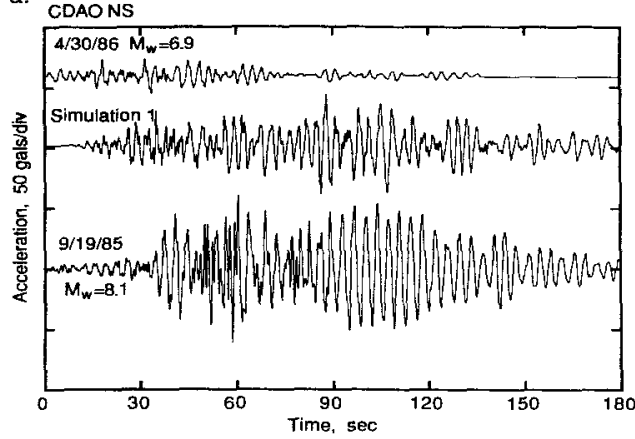

c.

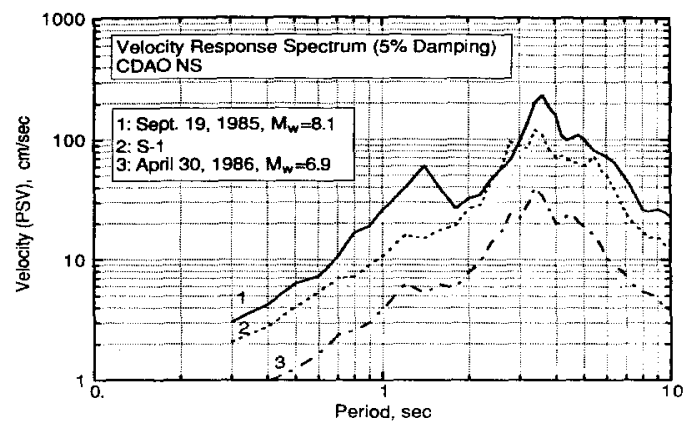

b. CDAO EW

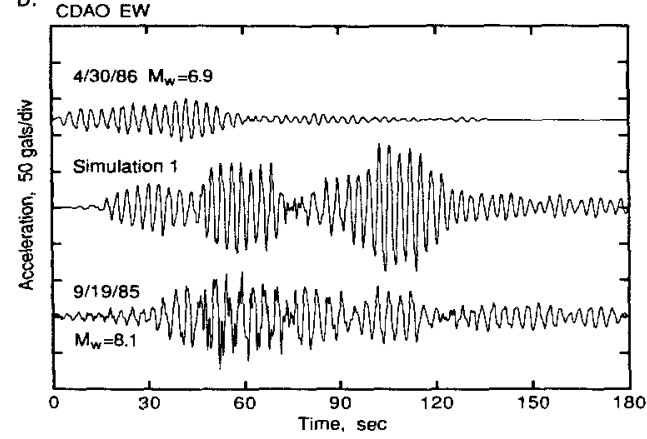

d.

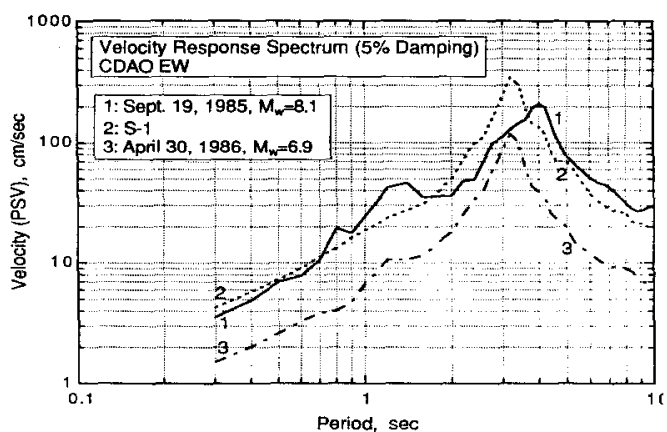

FIG. 4. (a) Time histories of $\mathrm{N}-\mathrm{S}$ ground-motion acceleration at the CDAO site in Mexico City. The top trace is the acceleration record of the 30 April 1986 earthquake, which is used for the empirical Green's function. The bottom trace is the acceleration record of the 19 September 1985 Michoacan earthquake, shown as reference. The middle traces are the simulated ground motion using the Michoacan rupture sequence shown in Figure 2. (b) Time histories of $E-W$ ground-motion acceleration at the CDAO site in Mexico City. (c) The velocity response spectra (5\% damping) computed for the time histories shown in Figure 4a. (d) The velocity response spectra (5\% damping) computed for the time histories shown in Figure $\mathbf{4 b}$. 
function. For the 30 April 1986 earthquake, we used the seismic moment $2 \times 10^{26}$ dyne-cm determined from body waves (Astiz et al., 1987). For the $\mathrm{E}-\mathrm{W}$ component, the spectral amplitude of the simulated motion is about twice as large as that observed at $3-\mathrm{sec}$ period, but is about $70 \%$ of the observed at 4 -sec period. The results for the $\mathrm{N}-\mathrm{S}$ component are qualitatively similar to those for the $\mathrm{E}-\mathrm{W}$ component. However, the ratio of the $\mathrm{E}-\mathrm{W}$ to the $\mathrm{N}-\mathrm{S}$ component is significantly different between the 30 April 1986 event and the main shock; this difference is reflected in the simulations and their spectra.

We did not include nonlinear behavior of the clay layer in our simulation, because Singh et al. (1988a) found no conclusive evidence for that. Romo and Jaime (referenced in Seed et al., 1988) showed that the reduction of shear modulus of the clay is only $10 \%$ even at strains as large as $0.15 \%$.

\section{Simulation for Events IN THE Guerrero SeISMic GaP}

\section{Guerrero Seismic Gap}

There is no widely accepted definition of the Guerrero seismic gap. In general, the southeastern end of the 1979 Petatlan earthquake is considered to be the northwestern edge of the Guerrero gap (Fig. 1). The southeastern end of the Guerrero gap cannot be defined very well. Because the 1957 Acapulco (San Marcos) event is relatively recent, this part of the subduction zone is not likely to produce a major seismic event in the near future. Between the locations of the 1957 event and the 1979 event a few large earthquakes occurred during the time period between 1899 and 1911. The size and the location of these events are not accurately known. However, none of these events seems to be as large as the 1985 Michoacan earthquake. To the southeast of Acapulco, a large earthquake occurred in 1907, which may have ruptured from Acapulco to the rupture zone of the 1982 Ometepec earthquake (see Fig. 1). The surface-wave magnitude of this earthquake is estimated to be about 7.7 (Abe and Noguchi, 1983; Anderson et al., 1989). This zone may have been reruptured in 1937, 1950 , and 1957, but the details are uncertain.

With this uncertainty in mind we will consider two models for the next Guerrero earthquake. The first model is the same as the 1985 Michoacan earthquake, and fills the entire gap between the 1979 event and the 1957 event. The second model follows the evidence that the previous activity during the period from 1899 to 1911 represents a sequence of events each smaller than the 1985 event. To model this situation we consider an event that represents the first half of the Michoacan sequence; this event corresponds to an event with $M_{w}=7.6$, and is considered an appropriate model for typical subduction zone earthquakes in Mexico.

\section{Green's Function}

We used the records from four recent earthquakes that occurred in or near the Guerrero gap; these events are listed in Table 2. For all of these earthquakes, accelerograms were obtained at the CDAO site in Mexico City. These records, shown in Figure 5, are used as the empirical Green's functions for simulation. We briefly describe these events below.

8 February 1988. This earthquake occurred near the northwestern edge of the Guerrero gap, near the 1979 Petatlan earthquake. According to the Monthly Listing of Earthquakes published by the National Earthquake Information 

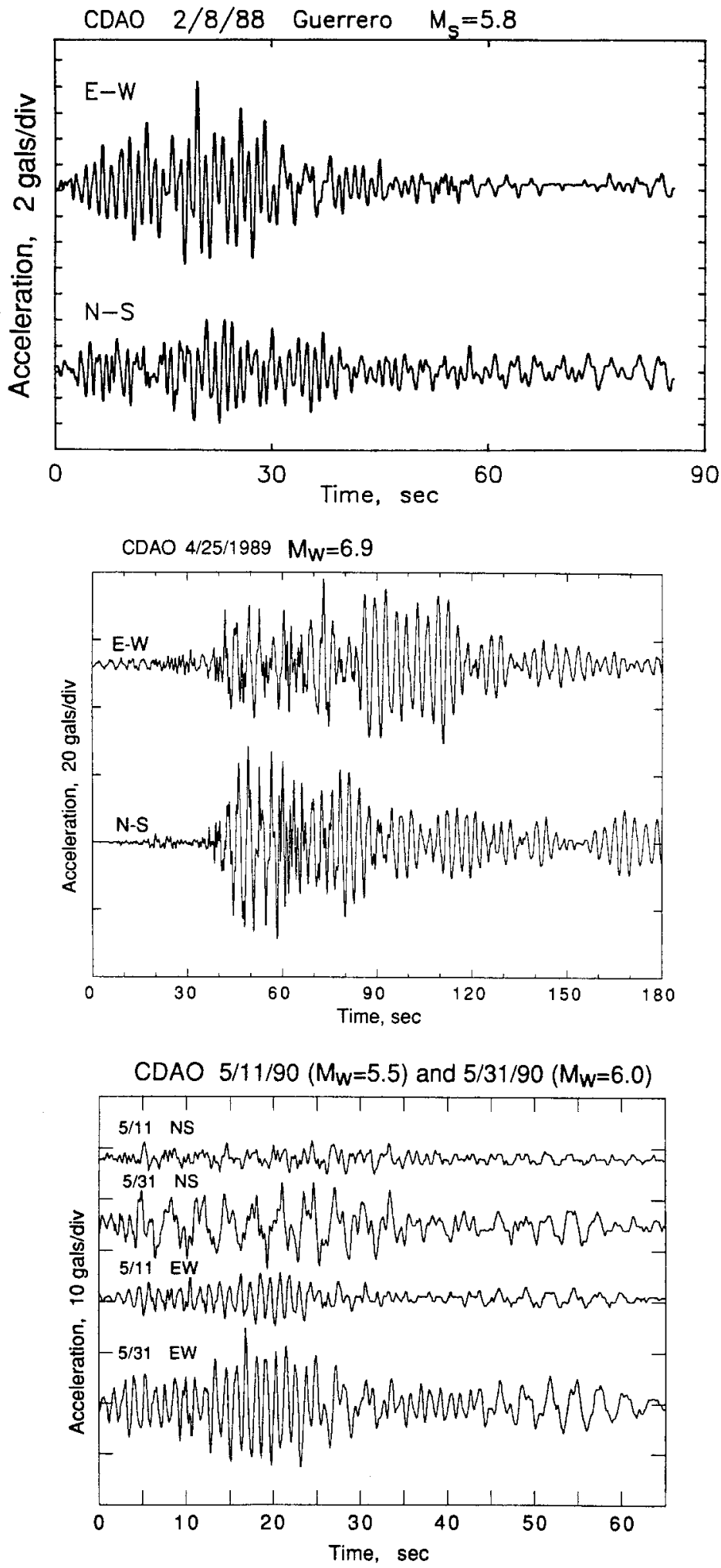

FIG. 5. Accelerograms recorded at CDAO for four earthquakes that occurred in the Guerrero seismic gap. These records are used as the empirical Green's functions. 
Service (NEIS), this earthquake was located at a depth of $58 \mathrm{~km}$. The Harvard Centroid Moment Tensor (CMT) has a very large (39\%) nondouble-couple solution and is located at a depth of $47.8 \mathrm{~km}$. The best double-couple solution is an oblique dip slip with a seismic moment of $7.4 \times 10^{24}$ dyne-cm. Because of the relatively small size of this event, this mechanism and the moment are not considered very reliable. However, the result from the local seismic network suggests that this is a thrust event typical of Mexican subduction-zone earthquakes. The depth estimated with the data from the local network is 10 to 20 $\mathrm{km}$. If the event is shallow, the CMT moment could have been overestimated. Because of the uncertainty in the mechanism and the moment, we use the records from this event assuming a seismic moment of $5 \times 10^{24}$ dyne-cm, and use the result only for comparison purposes.

25 April 1989. This earthquake occurred near Acapulco and is located by NEIS at a depth of $20 \mathrm{~km}$. We determined the mechanism and the seismic moment of this event using the broadband data recorded at stations PAS (Pasadena) and HVR (Harvard). The mechanism is a low-angle thrust event typical of Mexican subduction-zone earthquakes, and the seismic moment is $2.4 \times 10^{26}$ dyne-cm $\left(M_{w}=6.9\right)$. The Harvard CMT solution is very similar to this. This event is the best determined among all the reference events we used.

11 May and 31 May 1990. These two earthquakes occurred in the northwestern edge of the Guerrero gap, near the southeastern end of the 1979 Petatlan earthquake. The 31 May event is larger than the 11 May event. We determined the moment and the mechanism of the 31 May earthquake using the broadband records from PAS, HRV, ANMO (Albuquerque), and KIP (Kipapa). We obtained a thrust mechanism and a seismic moment of $1.1 \times 10^{25}$ dyne-cm $\left(M_{w}=6.0\right)$. The first-motion data from the local network also indicate a low-angle thrust mechanism. Thus, the records from this earthquake are appropriate for the empirical Green's functions to be used in the present simulation.

The waveform of the 11 May event recorded in Mexico City is very similar to that of the 31 May event (Figure 5), suggesting that the location and the mechanism of these two earthquakes are similar. From the seismic moment of the 31 May 1990 event and the magnitude difference of 0.5 between these two events, we estimate the seismic moment of the 11 May event to be $2 \times 10^{24}$ dyne-cm. The 11 May event is used only for comparison purposes.

\section{Simulation}

We performed simulations for three cases, S-1, S-2, and S-3, considering the variability of the rupture pattern in the Guerrero gap. The first model (S-1) is the same as the 1985 Michoacan earthquake in that the fault model of the 1985 Michoacan earthquake shown in Figure 2 is placed in the Guerrero gap without change. The second case (S-2) simulates the previous activity during the period from 1899 to 1911. During this period the Guerrero gap was filled with a series of events with $M_{s}=7.5$ to 7.8. We used the first half of the Michoacan sequence to simulate this event. Because the rupture pattern of the Guerrero earthquake can be different from that of the Michoacan earthquake, we considered a third case (S-3). We randomly moved the locations of all the subevents in Figure 2 by $\pm 20 \mathrm{~km}$ in both the strike and the down-dip directions. We also changed randomly the onset times of subevents by $\pm 5 \mathrm{sec}$. This perturbation is large enough to substantially destroy any space-time correlation that exists in the Michoacan earthquake. Because the data set for the CDAO site in Mexico City is most complete, we performed the simulation for this site. 
Figures $6 \mathrm{a}, 6 \mathrm{~b}, 6 \mathrm{c}$, and $6 \mathrm{~d}$ show the results of simulation using the records of the 8 February 1988 event as the Green's function. In these figures, simulation results are shown for the three cases, S-1, S-2, and S-3. Also, the acceleration records and the spectra of the empirical Green's function (8 February 1988 event) and the 19 September 1985 Michoacan mainshock are shown for comparison.

The simulated motions for case S-1 are more enriched in short period energy than the 1985 Michoacan event, especially for the $\mathrm{E}-\mathrm{W}$ component. For the $\mathrm{E}-\mathrm{W}$ component, the simulated motion is about 2 times larger than the Michoacan event at periods shorter than $3 \mathrm{sec}$ (Figure 6d). However, at periods longer than $3 \mathrm{sec}$, the Michoacan event has a larger spectral amplitude. The abundance of the short-period energy for the Guerrero event could be partly due to its shorter distance to Mexico City than the Michoacan event.

For S-2, the simulated motion is about $1 / 2$ of that for $\mathrm{S}-1$, and is significantly smaller than the ground motions for the Michoacan event at periods longer than 1 sec. For the $\mathrm{E}-\mathrm{W}$ component, the simulated motion is as much as a factor of 2 larger than the Michoacan event at some periods shorter than 1 sec. The duration of the ground motion is about half that of the Michoacan event, reflecting the small size of the fault plane for this model.
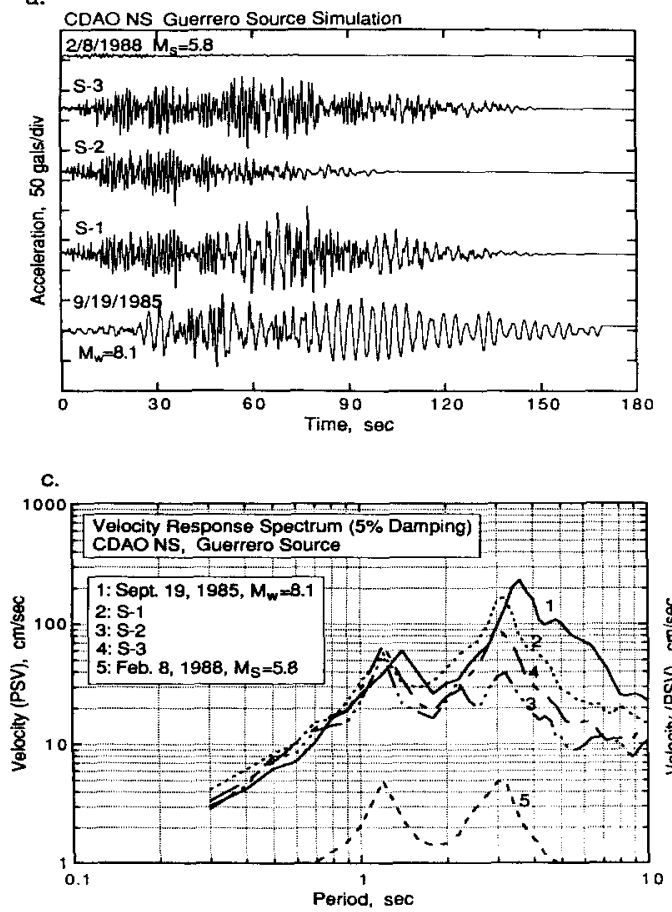

b.

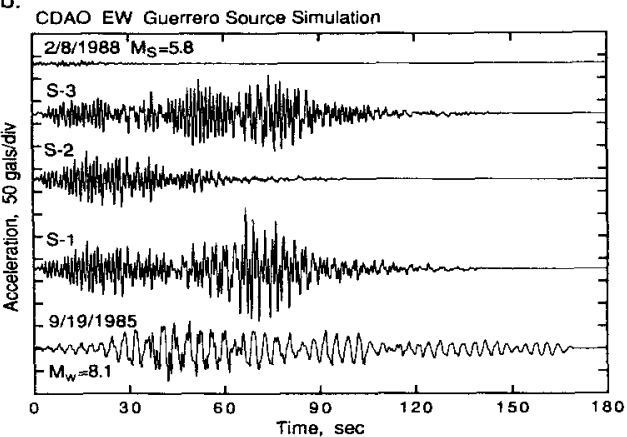

d.

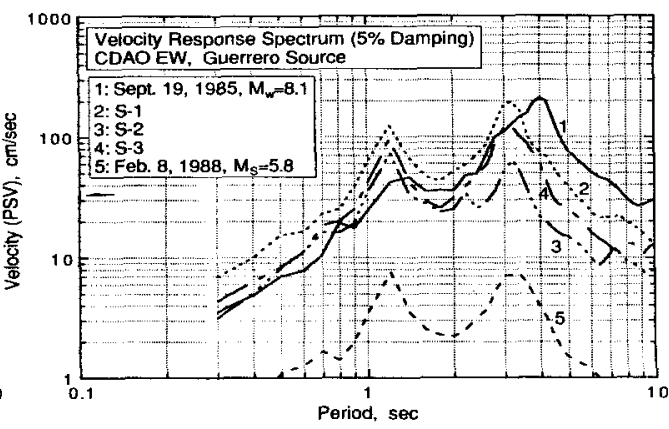

FIG. 6. (a) Time histories of $\mathrm{N}-\mathrm{S}$ ground-motion acceleration at the CDAO site in Mexico City computed for hypothetical Guerrero earthquakes. The top trace is the acceleration record of the 8 February 1988 earthquake, that is used for the empirical Green's function. The bottom trace is the acceleration record of the 19 September 1985 Michoacan earthquake, shown as reference. The middle three traces are simulated ground motions for the three models, S-1, S-2, and S-3. (b) Time histories of E-W ground-motion acceleration at the CDAO site in Mexico City. (c) The velocity response spectra ( $5 \%$ damping) computed for the time histories shown in Figure 6a. (d) The velocity response spectra ( $5 \%$ damping) computed for the time histories shown in Figure $6 \mathrm{~b}$. 
For S-3, the simulated motion tends to be about $30 \%$ smaller than that for S-2; i.e., randomizing the rupture pattern leads to an amplitude decrease of about $30 \%$.

Figures $7 \mathrm{a}, 7 \mathrm{~b}, 7 \mathrm{c}$, and $7 \mathrm{~d}$ show the time histories and response spectra of ground motions simulated using the record of 25 April 1989. Because the 25 April 1989 event is the largest of the reference events we used and its source parameters are best determined, we consider the simulation using this event the most realistic.

The spectral amplitude for S-1 is in general larger than that of the 1985 Michoacan earthquake by a factor of 2 , except for periods longer than $5 \mathrm{sec}$. The overall trend is similar to that obtained from the 8 February 1988 event. The amplitude of S-2 is comparable to the 1985 event for periods shorter than $3 \mathrm{sec}$, but is about a factor of 2 smaller for long periods.

Figures $8 \mathrm{a}, 8 \mathrm{~b}, 8 \mathrm{c}$, and $8 \mathrm{~d}$ show the time histories and response spectra of ground motions simulated using the record of 31 May 1990. The $\mathrm{E}-\mathrm{W}$ component of the simulated motion is significantly enriched with energy for periods shorter than $1 \mathrm{sec}$, whereas no such enrichment is seen for the $\mathrm{N}-\mathrm{S}$ component.

a. CDAO NS Guerrero Source Simulation

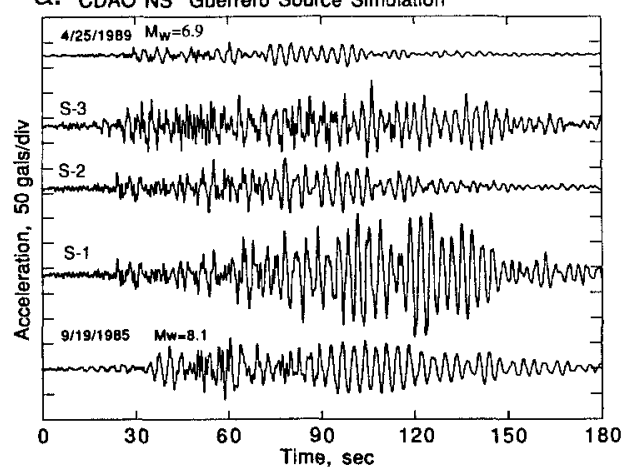

C.

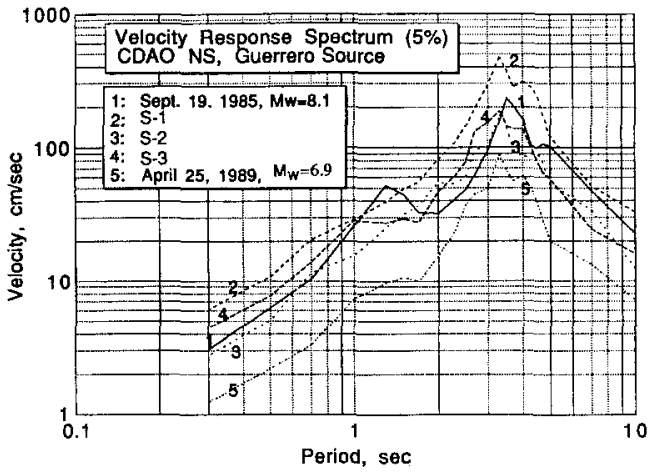

b. CDAO EW Guerrero Source Simulation

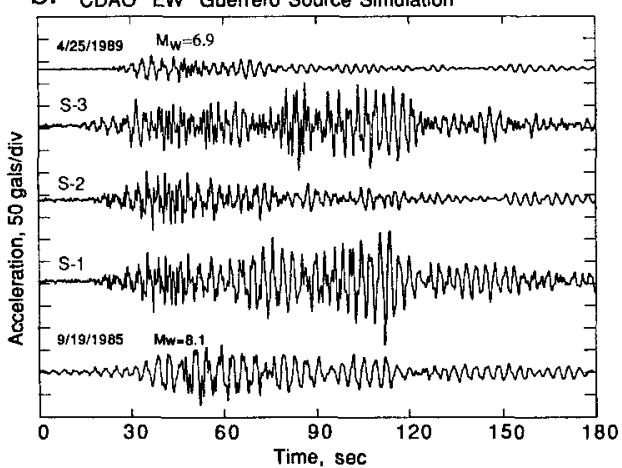

d.

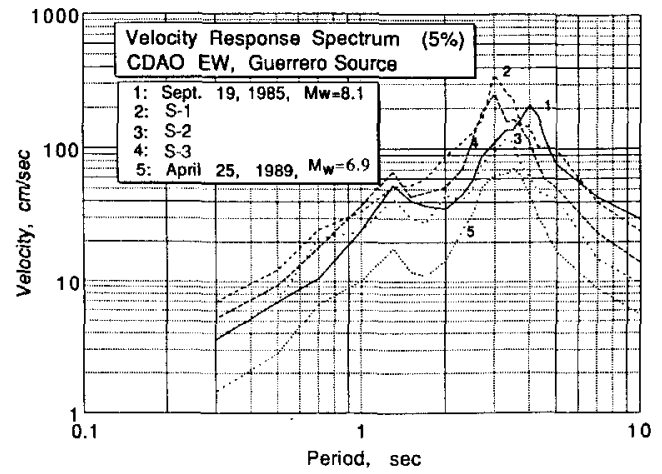

FIG. 7. (a) Time histories of $\mathrm{N}-\mathrm{S}$ ground-motion acceleration at the CDAO site in Mexico City computed for hypothetical Guerrero earthquakes. The top trace is the acceleration record of the 25 April 1989 earthquake, that is used for the empirical Green's function. The bottom trace is the acceleration record of the 19 September 1985 Michoacan earthquake, shown as reference. The middle three traces are simulated ground motions for the three models, S-1, S-2, and S-3. (b) Time histories of E-W ground-motion acceleration at the CDAO site in Mexico City. (c) The velocity response spectra ( $5 \%$ damping) computed for the time histories shown in Figure 7a. (d) The velocity response spectra (5\% damping) computed for the time histories shown in Figure $7 \mathrm{~b}$. 
a.

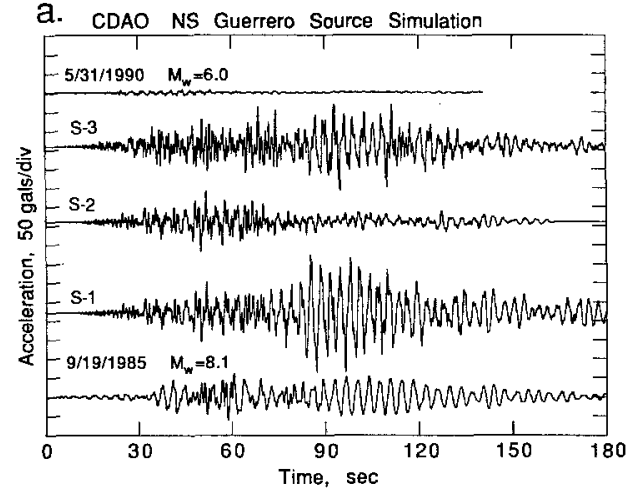

c.

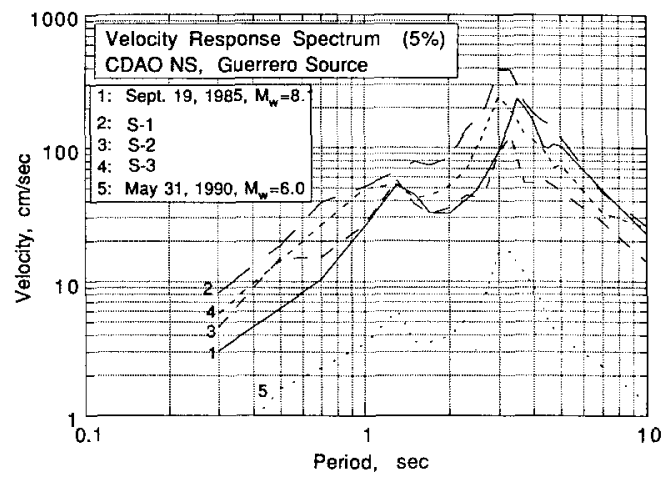

b. CDAO EW Guerrero Source Simulation

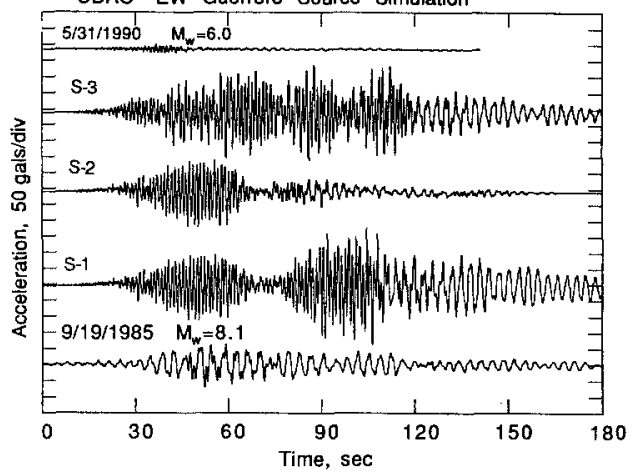

d.

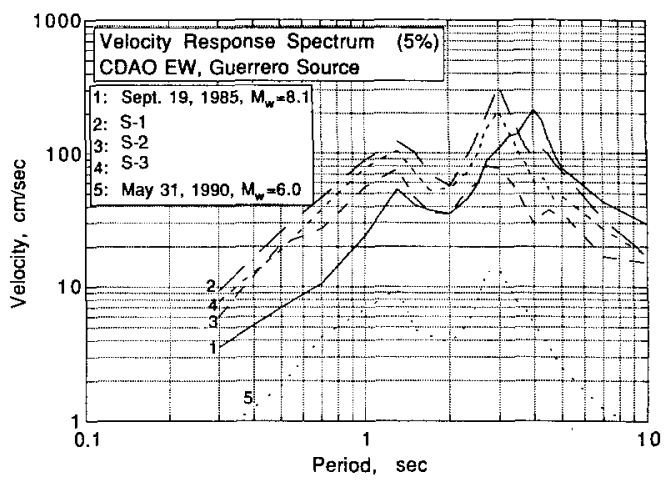

FIG. 8. (a) Time histories of N-S ground-motion acceleration at the CDAO site in Mexico City computed for hypothetical Guerrero earthquakes. The top trace is the acceleration record of the 31 May 1990, earthquake that is used for empirical Green's function. The bottom trace is the acceleration record of the 19 September 1985 Michoacan earthquake, shown as reference. The middle three traces are simulated ground motions for the three models, S-1, S-2, and S-3. (b) Time histories of E-W ground-motion acceleration at the CDAO site in Mexico City. (c) The velocity response spectra (5\% damping) computed for the time histories shown in Figure 8a. (d) The velocity response spectra (5\% damping) computed for the time histories shown in Figure $8 \mathrm{~b}$.

This difference is obvious in the acceleration records of both the 11 May and 31 May events, as shown in Figure 5. This result suggests that for earthquakes in the Guerrero gap, the $\mathrm{E}-\mathrm{W}$ component of the ground motions at CDAO may be significantly larger than the N-S component at periods shorter than 1 sec.

In all of these simulations, we noticed that the latter half of S-1 ground motions is significantly larger than the first half which is the S-2 ground motion. This is especially evident at periods of 2 to $4 \mathrm{sec}$, as shown in Figure 9. This suggests that the rupture pattern of the 1985 Michoacan earthquake caused constructive interference of subevent ground motions in the second half of the rupture, thereby enhancing the ground motion amplitude at these periods. This explains why the ground motion amplitude is significantly reduced when the rupture sequence is randomized as in S-3. From this observation we conclude that the 1985 Michoacan earthquake may be an unusual event in that it enhanced ground motions at periods of 2 to $4 \mathrm{sec}$. A similar conclusion was reached by Singh et al. (1988b, 1990).

Because we cannot predict the rupture sequence of the Guerrero earthquake exactly, we can only estimate the ground motion deterministically within broad limits. However, if the rupture pattern has coherence, similar to the 1985 
a.

Comparison of Ground Motion

First and Second Half of the Guerrero Rupture Sequence

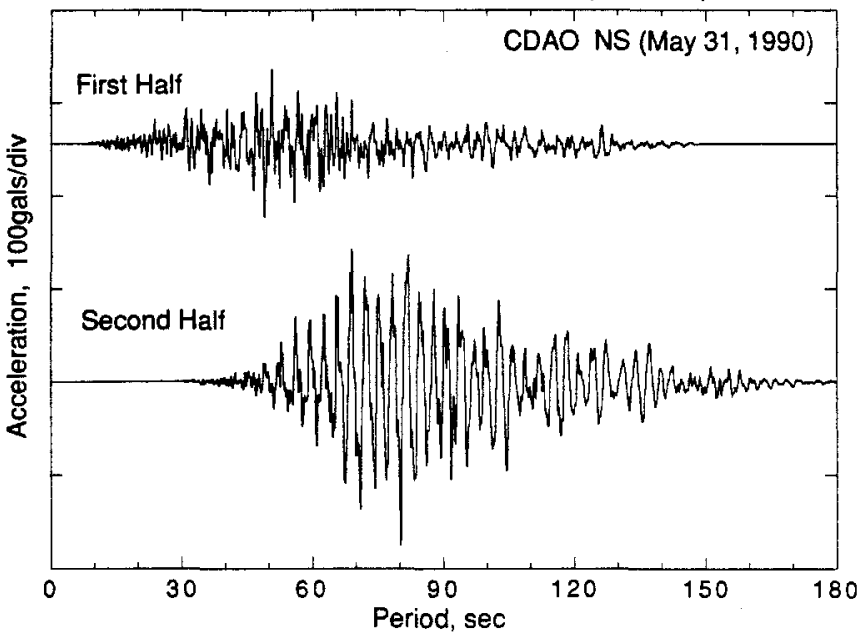

b.

Comparison of Velocity Response Spectrum First and Second Half of the Guerrero Rupture Sequence

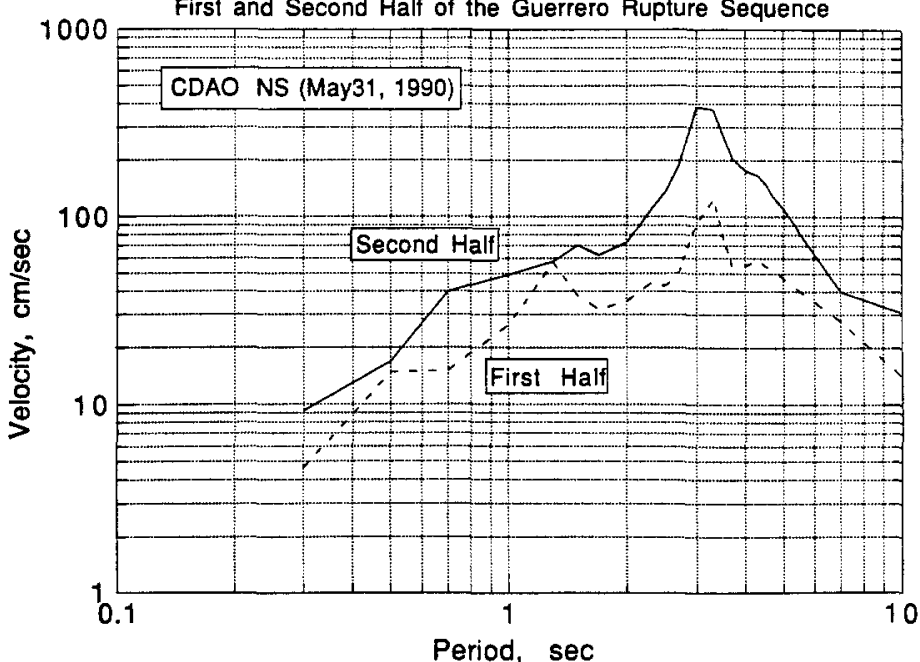

FIG. 9. (a) Simulated ground motion using the first (top trace) and the second (bottom trace) half of the rupture sequence of the 1985 Michoacan earthquake. The 31 May 1990 event is used as the Green's function. (b) The response spectra of Figure 9a.

Michoacan sequence, significant enhancement of ground motion is expected, as seen in our simulations. If the rupture sequence is more random, smaller ground motions are expected. The example of the Michoacan event clearly illustrates the importance of the rupture pattern in affecting the amplitude of ground motions.

\section{DESTGN SPECTRA}

The spectra of the simulated motions shown in the previous sections can be used directly to guide the design or retrofit of structures to resist the shaking 
expected from future earthquakes in the Guerrero gap, but it is more useful for many applications to have smooth design spectra of the type widely used in engineering practice.

Figure 10 shows the design spectra for the CDAO site constructed from the results shown in Figures $6 \mathrm{c}, 6 \mathrm{~d}, 7 \mathrm{c}, 7 \mathrm{~d}, 8 \mathrm{c}$, and $8 \mathrm{~d}$. In constructing the design spectra, we gave more weight to the results of the simulation using the 25 April 1989 earthquake because the empirical Green's functions used are the largest and the source parameters are best determined. The heavy solid lines in these figures denote a $5 \%$ damped design spectra appropriate for simulation $\mathrm{S}-1$, the motion that might be generated if the entire gap is broken by one great earthquake. Similarly, the heavy dashed lines show design spectra suggested for simulation S-2, the case in which the Guerrero gap is filled by two somewhat smaller earthquakes.

The design spectra shown in Figure 10 are for elastic response and have not been reduced in anticipation of ductile response or for other response beyond the elastic limit. Depending on the type of construction, the importance of the structure and other parameters, the U.S. practice permits reduction factors of 3 to 8 or higher when reducing the level of forces indicated by the elastic spectra to forces used for linear design at code-level stresses. The indicated deflections are not usually reduced, so the intended result is a design that resists the earthquake motions at the displacement levels of the original design spectra, but with ductile response at force levels determined by the elastic limits of the materials. At the high levels of response demanded by extremely strong ground motion, the response necessarily is associated with some structural and nonstructural damage, but it is intended that hazardous levels of damage be prevented.

Appropriate to the uncertainties of the simulations, the design spectra shown in Figure 10 have a flat central portion that is considerably broader than the

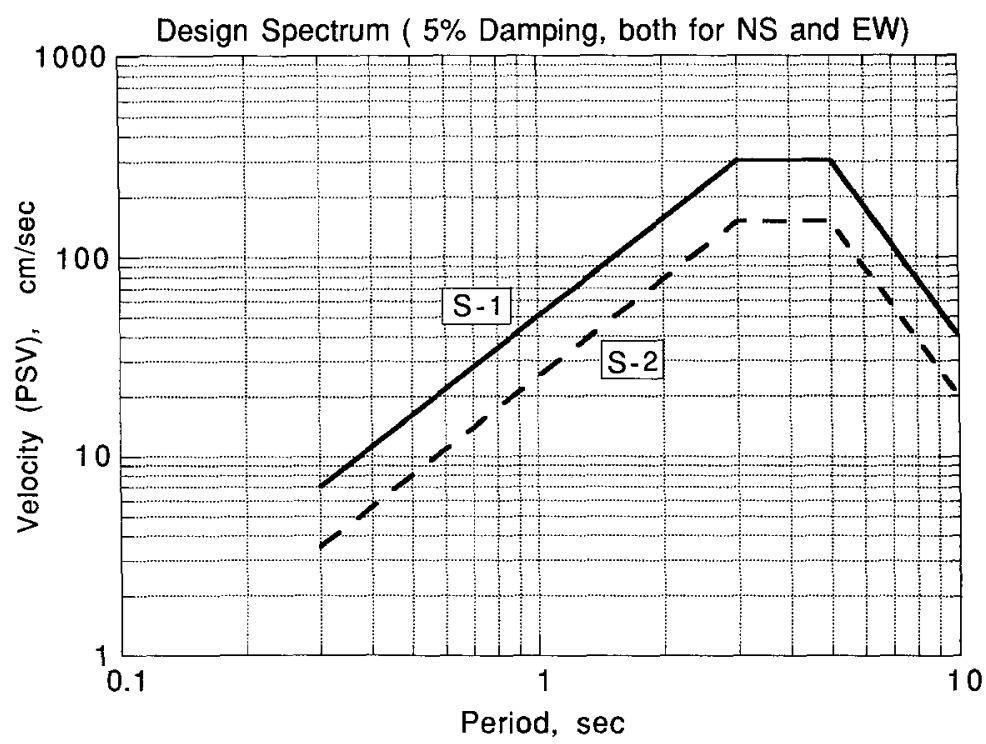

FIG. 10. The design spectra (5\% damping) for the CDAO site derived from the response spectra shown in Figures 6, 7, and 8. 
individual spectral peaks of the simulations or the actual recorded motions. The design spectra are also constructed to accommodate what may be the second mode of the soil profile which occurs fairly consistently at about $1.4 \mathrm{~s}$.

The level of the spectra covers the smaller peaks of the simulations, but does not exceed the major peaks of the spectra of the simulations in all cases. Some exceedance of the design by peaks of individual motions of earthquakes of the expected size is to be expected as it is unreasonably conservative in most applications for design spectra to be an upper bound for all possible motions of the design level. It is also noted that the simulation process used is entirely linear and does not account for the increasing ability of the soil to dissipate energy as the amplitude of the input increases.

Although the simulated motions do not show systematic differences between the components at periods longer than $2 \mathrm{sec}$, we found that, at periods shorter than 2 sec, the $\mathrm{E}-\mathrm{W}$ component is systematically larger than the N-S component at CDAO. This difference needs to be considered in using the design spectra shown in Figure 10 at periods shorter than 2 sec.

Rosenblueth et al. (1989) have discussed the design spectra adopted in the 1987 building code for Mexico's Federal District. The code design spectrum for the lake bed zone and the spectra in Figure 10 are generally similar, crossing once and differing less than a factor of 2 over this common range of periods. However, direct comparison is complicated by the different approaches used in their development and in the application of reduction factors.

\section{Discussion}

Because the method involves no free parameters, the results obtained here are considered robust. However, the results depend on the character of the event used as the Green's function, the scaling relation used to determine the spectra of subevents, and the details of the rupture pattern.

The scaling relation used in this study is one of the simplest ones that is consistent with the Mexican subduction zone. A use of different scaling relations will result in somewhat different results. However, any scaling relation that is consistent with the events in Mexico is expected to yield similar simulated ground motions. For example, a change in the stress parameter from 5 to 200 bars results in only a $15 \%$ change in the amplitude of simulated motion. The reason for this insensitivity can be understood as follows. The value of $\Delta \sigma$ affects the simulation result through the $\left(\omega^{2}+\omega_{r}^{2}\right) /\left(\omega^{2}+\omega_{i}{ }^{2}\right)$ term of the right-hand side of equation (6). If the size of the reference event is about the same as that of the subevents, then $\omega_{r}$ and $\omega_{i}$ are about the same so that the value of $\Delta \sigma$ does not influence the result strongly. In our case the size of the most important reference events, the 25 April 1989, and 31 May 1990 earthquakes is about the same as that of the subevents of the Michoacan sequence (see Table 1). Also, the frequency range of our interest is considerably higher than the corner frequencies of most of the subevents and the reference events so that the $\left(\omega^{2}+\omega_{r}^{2}\right) /\left(\omega^{2}+\omega_{i}^{2}\right)$ term of equation (6) is relatively insensitive to $\omega_{r}$ and $\omega_{i}$.

We ignored the difference in the phase spectrum between the reference event and the subevents. However, as mentioned above, the size of the reference events is about the same as the subevents so that the neglect of the phase difference should not affect the results significantly. In any case, the overall duration of the simulated motions is primarily controlled by the duration of the 


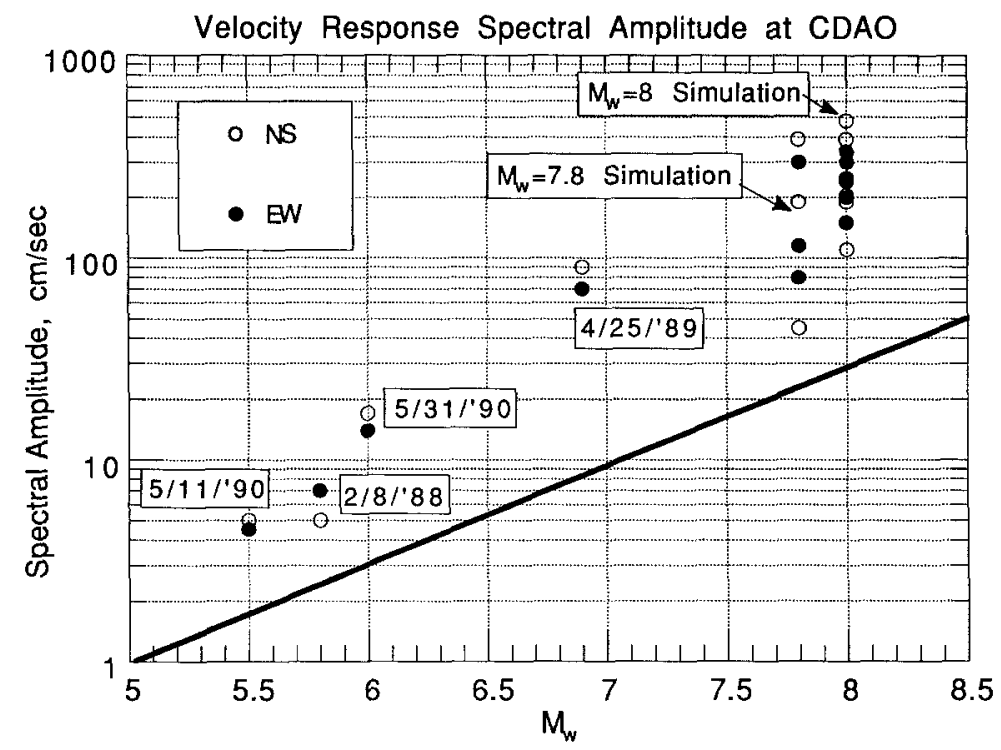

FIG. 11. The peak velocity response spectral amplitudes for the observed and simulated ground motions as a function of the moment magnitude $M_{w}$. A slope of $1 / 2$ is indicated by the straight line.

rupture sequence, and the neglect of the phase difference does not affect the overall character of the time history.

In order to see the overall consistency of our simulation, we compare our simulated ground motions for various cases with the observed ground motions in Figure 11 which shows the peak spectral amplitude for various simulations and the observed motions as a function of the moment magnitude $M_{w}$. The spectral amplitudes of the simulated motions are more or less on the extrapolated trend of the observed spectral amplitudes indicating that the results of our simulation are reasonable on this empirical basis. In Figure 11, the solid line indicates a slope of $1 / 2$. At frequencies higher than the corner frequency, we obtain, combining equations (2) and (3), $\log \hat{\dot{M}}(\omega) \approx(1 / 3) \log M_{0}$. Since $\log M_{0} \approx$ $1.5 M_{w}$, a slope of $1 / 2$ is then expected on a $\log \hat{\dot{M}}(\omega)$ versus $M_{w}$ diagram. In Figure 11, the trend of the data is approximately $1 / 2$, indicating that our results are, in general, consistent with the $\omega^{2}$ model.

\section{CONCLUSION}

If the Guerrero event is similar to the 1985 Michoacan event, our analysis indicates that the resulting ground motion in Mexico City will be approximately twice as large as that of the 1985 Michoacan earthquake at periods longer than 2 sec. At periods shorter than $2 \mathrm{sec}$, the expected amplitude is 2 to 3 times larger than that for the Michoacan earthquake.

If the events in the Guerrero seismic gap occur as a sequence of magnitude 7.5 to 7.8 events, as they did in the previous sequence around the turn of the century, the strong motion in Mexico City is estimated to be about half that experienced during the 1985 Michoacan earthquake at periods longer than 2 sec. However, several factors affect this estimate. The magnitude of the possible events has a significant range and, if a rupture sequence is such that it 
enhances ground-motion amplitude with constructive interference, as occurred during the second half of the Michoacan sequence, some components of the ground motion could be amplified by a factor of 2 to 3 .

\section{ACKNOWLEDGMENTS}

This work was partially supported by NSF grant ECE 86-10994 and U. S. Geological Survey Grant 14-08-0001-G1356. Contribution no. 5148, Division of Geological and Planetary Sciences, California Institute of Technology.

\section{REFERENCES}

Abe, K. and S. Noguchi (1983). Revision of magnitudes of large shallow earthquakes, 1897-1912, Phys. Earth and Planet. Int. 33, 1-11.

Anderson, J. G., P. Bodin, J. N. Brune, J. Prince, S. K. Singh, R. Quaas, and M. Onate (1986). Strong ground motion and source mechanism of the Mexico earthquake of September 19, 1985 $(\mathrm{Ms}=8.1)$, Science 233, 1043-1049.

Anderson, J. G., S. K. Singh, J. M. Espindola, and J. Yamamoto (1989). Seismic strain release in the Mexican subduction thrust, Phys. Earth Planet. Int. 58, 307-322.

Astiz, L. and H. Kanamori (1984). An earthquake doublet in Ometepec, Guerrero, Mexico, Phys. Earth Planet. Int. 34, 24-25.

Astiz, L., H. Kanamori, and H. Eissler (1987). Source characteristics of earthquakes in the Michoacan seismic gap in Mexico, Bull. Seism. Soc. Am. 77, 1326-1346.

Boore, D. M. (1983). Stochastic simulation of high-frequency ground motions based on seismological models of the radiated spectra, Bull. Seism. Soc. Am. 54, 1865-1894.

Brune, J. N. (1970). Tectonic stress and the spectra of seismic shear waves from earthquakes, J. Geophys. Res. 75, 4997-5009.

Brune, J. N. (1971). Correction, J. Geophys. Res. 76, 5002.

Eissler, H., L. Astiz, and H. Kanamori (1986). Tectonic setting and source parameters of the September 19, 1985 Michoacan, Mexico earthquake, Geophys. Res. Lett. 13, 569-572.

Ekström, G. and A. M. Dziewonski (1986). A very broad band analysis of the Michoacan, Mexico, earthquake of September 19, 1985, Geophys. Res. Lett. 13, 605-608.

Hartzell, S. H. (1978). Earthquake aftershocks as Green's functions, Geophys. Res. Lett. 5, 1-4.

Hartzell, S. H. and T. H. Heaton (1985). Teleseismic time functions for large, shallow subduction zone earthquakes, Bull. Seism. Soc. Am. 75, 965-1004.

Houston, H. (1987). Source characteristics of large earthquakes at short periods, thesis, $129 \mathrm{pp}$., California Institute of Technology, Pasadena.

Houston, H. and H. Kanamori (1986a). Source characteristics of the 1985 Michoacan, Mexico earthquake at periods of 1 to 30 seconds, Geophys. Res. Lett. 13, 597-600.

Houston, H. and H. Kanamori (1986b). Source spectra of great earthquakes: teleseismic constraints on rupture process and strong motion, Bull. Seism. Soc. Am. 76, 19-42.

Kanamori, H. (1979). A semi-empirical approach to prediction of long period ground motions from great earthquakes, Bull. Seism. Soc. Am. 69, 1645-1670.

Mendez, A. J. and J. G. Anderson (1991). The temporal and spatial evolution of the 19 September 1985 Michoacan earthquake as inferred from near-source ground-motion records, Bull. Seism. Soc. Am. 81, 844-861.

Mendoza, C. and S. H. Hartzell (1989). Slip distribution of the 19 September 1985 Michoacan, Mexico, earthquake; near-source and teleseismic constraints, Bull. Seism. Soc. Am. 79, $655-669$.

Rosenblueth, E., M. Ordaz, F. J. Sanchez-Sesma, and S. K. Singh (1989). The Mexico earthquake of September 19, 1985-Design spectra for Mexico's federal district, Earthquake Spectra 5, 273-291.

Sanches-Sesma, F., S. Chavez-Perez, M. Suarez, M. A. Bravo, and L. E. Perez-Rocha (1988). The Mexico Earthquake of September 19, 1985-On the seismic response of the valley of Mexico, Earthquake Spectra 4, 569-589.

Seed, H. B., M. P. Romo, J. I. Sun, A. Jaime, and J. Lysmer (1988). The Mexico earthquake of September 19, 1985-Relationships between soil conditions and earthquake ground motions, Earthquake Spectra 4, 687-729. 
Singh, S. K., L. Astiz, and J. Havskov (1981). Seismic gaps and recurrence periods of large earthquakes along the Mexican subduction zone: A reexamination, Bull. Seism. Soc. Am. 71, $827-843$.

Singh, S. K., J. Lermo, T. Dominguez, M. Ordaz, J. M. Espinosa, E. Mena, and R. Quaas (1988a). The Mexico earthquake of September 19, 1985-A study of amplification of seismic waves in the valley of Mexico with respect to a hill zone site, Earthquake Spectra 4, 653-674.

Singh, S. K., E. Mena, and R. Castro (1988b). Some aspects of source characteristics of the 19 September 1985 Michoacan earthquake and ground motion amplification in and near Mexico City from strong motion data, Bull. Seism. Soc. Am. 78, 451-477.

Singh, S. K., A. Mori, E. Mena, F. Kruger, and Kind R. (1990). Evidence for anomalous body-wave radiation between 0.3 and $0.7 \mathrm{~Hz}$ from the 1985 Michoacan, Mexico, earthquake, Geophys. J. Int. 101, 37-48.

UNAM Seismology Group (1986). The September 1985 Michoacan earthquakes: aftershock distribution and history of rupture, Geophys. Res. Lett. 13, 573-576.

Zhuo, Y. and H. Kanamori (1987). Regional variation of the short-period (1 to $10 \mathrm{sec}$ ) source spectrum, Bull. Seism. Soc. Am. 77, 514-529.

\section{SEISMOLOGICAL LABORATORY \\ CALIFORNIA Institute of TECHNOLOGY \\ PASAdena, CAlifornia 91125 \\ (H. K., L. A.)}

Division of ENGINEERING AND APPLIED SCIENCES

CALIFORNIA INSTITUTE OF TECHNOLOGY

Pasadena, California 91125

(P. C. J.)

Manuscript received 29 April 1992
INSTITUTO DE INGENIERIA, UNAM

CiUdAD UNIVERSITARIA

APARTADO POSTAL 70-472

COYOACAN 04510

MEXico, D.F.

(S. K. S.) 